Article

\title{
Bridging the Digital Divide for Older Adults via Observational Training: Effects of Model Identity from a Generational Perspective
}

\author{
Qi Ma ${ }^{1, *}$, Alan H. S. Chan ${ }^{2}$ and Pei-Lee Teh ${ }^{3}$ (D) \\ 1 School of Public Administration, Beihang University, Beijing 100191, China \\ 2 Department of Systems Engineering and Engineering Management, City University of Hong Kong, \\ Kowloon Tong, Hong Kong; alan.chan@cityu.edu.hk \\ 3 School of Business, Gerontechnology Laboratory, Monash University Malaysia, Selangor Darul Ehsan 47500, \\ Malaysia; teh.pei.lee@monash.edu \\ * Correspondence: maqi525@buaa.edu.cn
}

Received: 10 April 2020; Accepted: 2 June 2020; Published: 3 June 2020

check for updates

\begin{abstract}
The proliferation of technology offers potential solutions for enhancing the well-being of older adults. However, older adults often have low digital literacy and are disengaged from the digital world. With age-appropriate training, older adults are expected to acquire a wide range of technological skills and bridge the digital divide. Through the lens of social cognitive theory, this study aims to investigate the effectiveness of observational training through behavior modeling in enhancing technology acceptance in older adults. The moderating effects of model identity on training outcomes from a generational perspective are examined. An empirical training experiment was completed with 59 community-dwelling older adults. Training outcomes were measured using cognitive knowledge, affective variables, and meta-cognition. The results ascertain the effectiveness of observational training in improving their technological knowledge, self-efficacy, outcome expectations, and sense of social connectedness when using technologies. From a generational perspective, the older adult behavior model is more effective than the young or child behavior models in increasing self-efficacy and willingness to use technology. The model identity further enhances the positive outcomes of training. The results of this study contribute to designing educational interventions to bridge the digital divide.
\end{abstract}

Keywords: digital divide; older adults; aging; training; technology acceptance; model identity; generation

\section{Introduction}

\subsection{Age-Related Digital Divide}

Global aging has brought new challenges for social sustainability. The population aged 60 and above has become the fastest growing segment worldwide as birth rate declines and life expectancy increases. In the short-to-medium term, high numbers of older people are inevitable. To keep older people healthy, independent, and active at work or in their community, social infrastructures and services must be accessible to them. Along with the aging trend, the technological revolution offers a great degree of accessibility for most people to fulfill various purposes, such as information and communication, entertainment, social support, leisure, work, and relationship maintenance [1]. Existing research indicates that technology can considerably increase the independence of older people [2]. The proliferation of technologies around the world, such as computer networks and mobile devices, offers various new channels for reaching older people, for example, by delivering messages 
related to health, security, or environmental hazards via a short message service or mobile apps. Technological devices and applications have a wide variety of practical benefits for elderly users, such as Internet-connected computers and smartphones granting users unprecedented access to information that can improve daily living, as well as providing new methods of communication to help reinforce old relationships and social ties or to develop new relationships [3].

Society is also moving toward a knowledge-based economy. This new economy has been accompanied by a rapid development in information technology. The increasing permeation of technology has led to the challenge of everybody requiring interaction with technological innovations in their everyday life; however, the current cohort of older people have only experienced technological products for a relatively short period late in their lives [4]. Despite the enhanced ease of use of technological devices for older adults, a digital divide remains [5]. Older adults continue to encounter obstacles preventing them from effectively using new technology $[6,7]$ and are less likely to adopt new technology than younger generations [8]. Limited access and low technological literacy are key reasons why older adults are excluded from being fully engaged in the digital world.

The current and future technological development depends on the level of technological knowledge and acceptance of the technology by society [9]. For a long time, a common opinion was that the digital divide problem was the result of a lack of physical access which can be solved when a country's Internet connection rate reaches saturation [10]. However, with the popularity of common digital technologies, such as smartphones, among older people, the digital illiteracy dimension is perhaps the most relevant reason leading to the digital divide. The notion of the second-level digital divide should be explored, in this context, to investigate the varying levels of use and skill, especially among older adults. Apart from who owns the technology (i.e., the first level), the question of who has the technological knowledge and usage skills (i.e., the second level) that distinguish them from others should also be explored [11]. One way of keeping older adults engaged and maintaining their well-being is to decrease the second-level digital divide, which is related to actual technology usage skills [12].

\subsection{Training as a Solution}

The use of educational services increases the quality of aging [13]. Launching new technology products is often achieved optimally through educational programs such as training and, therefore, training is expected to play a role as an underlying technique to help older people to adopt technology [14,15]. Researchers have suggested that one way of keeping older adults engaged and maintaining their well-being as they age is to decrease the second-level digital divide, which is related to actual technology usage and the skills in using technologies [12]. The work of Cotten et al. [3] provided the latest research and design-based recommendations for how to design and implement a technology training program for older adults in continuing care retirement communities (CCRCs), and their results showed that older adults in CCRCs can overcome the digital divide, reconnect with family and friends, and gain skills to enhance their quality of life.

Many previous studies have suggested that attending technology training programs or workshops can facilitate the development of self-confidence among older adults [16], elicit positive attitudes [17], and enhance positive social interactions [18]. Older adults are more comfortable with and willing to adopt new technologies and digital applications if they receive some form of technology training or support $[19,20]$. Given their relative inexperience with certain technologies, older adults may have much to gain from technology training [21]. To bridge the digital divide, the availability of help and support to older adults is critical for their acceptance and use of a technology $[19,22]$. With age-appropriate training approaches, older adults can and will learn a wide range of technology skills that can be incorporated into the Internet services provided to them [23]. Some studies have found that the difference between younger and older people not only relates to their actual knowledge of information technology but also to their cognition, such as their confidence in using the technology [24,25]. Training not only develops skills but also positively influences both the behavior intention and self-efficacy of recipients 
toward using the technology [26]. Renaud and Van Biljon [27] highlighted the connection between availability of social and technical support with exploration, actual use, and acceptance. Czaja et al. [28] emphasized that good instructional design for older adults is generally good instructional design for all. The design of any training or instructional program should be based on existing knowledge about how people learn and how best to teach them [28]. Tsai et al. [29] suggested that training programs that are specially designed for older adults and continued support are needed to help older adults explore technologies and facilitate their learning process. With the fast development of emerging ICT devices, it is necessary to dive deeper into developing appropriate cognitive interventions and training approaches for older adults [30]. Therefore, this study aims to develop a training model and to investigate the specific effectiveness of such training in enhancing older people's technology acceptance and use.

\section{Theoretical Background}

\subsection{Technology Acceptance}

One of the most important research needs for technology design guidelines to support older adults is identifying the factors that affect their technology acceptance [31]. Models of technology acceptance are useful, as they aid in identifying the facilitators and barriers to technology use and adoption and guide the design of devices and interventions to support technology use [28]. The problem of technology acceptance by older adults has been studied frequently in recent years, and a range of alternative theories and models have been proposed and extended to understand the digital divide problem.

In general, there are several prevalent models that can be used to interpret technology acceptance behaviors. Fishbein and Ajzen's theory of reasoned action (TRA) [32] and Ajzen's theory of planned behavior (TPB) [33] have been widely used, not only for technology acceptance but also for other behaviors. For specific models, the technology acceptance model (TAM) [34] and innovation diffusion theory (IDT) [35] are specially tailored to interpreting technology acceptance behaviors in work contexts or organizational environments. In another instance, Davis [34] introduced the concept of individual technology acceptance in the information systems literature. Additionally, the united theory of acceptance and usage of technology (UTAUT), derived by Venkatesh et al. [36], unifies the constructs of eight competing theoretical models, including TAM. These theories rely on the psychological construct of behavioral intention as a dependent variable, which indicates that a behavior is the result of an intention to carry it out.

TAM, UTAUT, and other models have been frequently applied and adapted to investigate the factors that influence the usage of technology of older adults. Renaud and Van Biljon [27] developed the Senior Technology Acceptance Model (STAM), which accounts for the context of technology acceptance factors and the adoption of technology. STAM posits that facilitating conditions, perceived usefulness, and the ease of learning influence the actual use of new technology. Barnard et al. [26] proposed a framework to explain the rejection or acceptance situations of new technologies and indicated that older adults hold positive attitudes toward learning and ideas about the difficulty of learning a new technology. Chen and Chan [37] successfully extended the TAM and incorporated variables from the UTAUT to build the senior technology acceptance model (STAM), which identifies important determinants such as usefulness, ease of use, facilitating condition, and self-efficacy. Recently, Tsai et al. [29] developed the senior technology exploration, learning, and acceptance (STELA) model through a longitudinal study, which examines the technology exploration and learning process in the changing technological environment. The STELA model identifies the relationship between exploration and difficulty of learning in the technology-learning processes of older adults. These senior technology acceptance studies are in agreement with the importance of technology training and supports. 


\subsection{Observational Learning of Social Cognitive Theory}

There has been a growth in studies focusing on the best practices in teaching new users how to adequately use a new technology. One of the most prevalent theories used to understand participant learning in education and information systems is social cognitive theory (SCT) [38]. SCT has been widely used as a powerful mechanism to understand human agency in social learning. The theory proposes that part of an individual's knowledge acquisition process can be directly achieved by observing others within the context of social interactions, experiences, and external media influences. According to SCT, watching others performing a behavior influences an observer's perceptions of their own ability to perform the behavior (or self-efficacy) and the expected outcomes that they perceive, as well as providing strategies for effective performance [39,40]. With modifications, SCT has become highly applicable in the context of information technology training to enhance the technological skills and acceptance of learners [12,41,42].

Observational learning, defined as people learning from observing others performing a behavior, is the essential theme of SCT [38]. Observational learning is achieved through the behavior modeling method, wherein learners can acquire knowledge by observing other people displaying behaviors that are associated with performing a task [43]. Much of the information technology training literature has focused on behavior modeling as an effective method of observational learning [40]. Such modeling emphasizes the importance of encouraging the recipients to act and respond similarly to specified behavior models regarding behaviors, attitudes, and emotional reactions in the same situations. This method not only yields better performance but is also associated with more positive reported evaluation, less negative affect, and greater satisfaction during training [40]. It has been studied in acquisition skills for computer use [44], in end-user software training for younger people [41,42,45], and in intervening with online consumer purchase opinions [46]. In particular, behavior modeling through videotaped demonstrations with a human model is popular and cost-effective [42,47]. However, for older adults, apart from the study of Struve and Wandke [48], which demonstrated the usefulness of video modeling in training older adults to use a ticket vending machine, there is a lack of research on the design features, effectiveness, and outcomes of video modeling for training older adults to use innovative technology and relevant applications, such as computer tablets, smartphones, and mobile applications. The salience of observational training via behavior modeling is unclear in improving digital literacy and enhancing technology acceptance. Its effectiveness among older adults should be investigated and the related outcomes should be measured. Thus, the following hypotheses are proposed:

Hypothesis 1 (H1). Observational training of digital devices and services will increase digital literacy and technological skills for older adults.

Hypothesis 2 (H2). The outcomes of observational training will enhance the intention of older adults toward information technology acceptance.

\subsection{Cognitive Determinants of Individual Behavior}

According to SCT, two sets of forces represent the primary cognitive determinants of individual behavior. The first set relates to behavior outcomes. Outcome expectation is the probabilistic belief of a person that a given outcome will result through the engagement of a specific behavior. Through the lens of SCT, individuals are more inclined to undertake behaviors that they believe will result in valued outcomes than those that they do not consider as having favorable consequences [27,38]. Previous studies have revealed that the expected outcomes of using technology significantly influence technology adoption in older adults $[49,50]$. However, research on how to bring about relevant and valued outcome expectations regarding the use of information technology by older adults is lacking. Thus, the following hypothesis is proposed: 
Hypothesis 3 (H3). The outcome expectations of older adults when using technology will be improved after observational training.

The second set of forces that determine individual behaviors encompasses what Bandura [38] calls "self-efficacy", or a belief about one's ability to perform a particular behavior. Self-efficacy influences choices about which behaviors to undertake and the effort exerted upon encountering obstacles to the performance of those behaviors. Many studies have indicated that self-efficacy influences the intention of older adults to use technology, specifically computers and the Internet [12,50,51]. A stronger self-efficacy contributes to technology acceptance in older adults [52]. Barnard et al. [26] have indicated that self-efficacy and the intention to learn technology in older adults may increase experimentation with and exploration of a new technology. To our knowledge, there are very few studies that have empirically investigated the effectiveness of observational training in enhancing the self-efficacy of older adults when using technology. Thus, the following hypothesis is proposed:

Hypothesis 4 (H4). The self-efficacy of older adults when using technology will be improved after observational training.

Apart from outcome expectations and self-efficacy, social connectedness has been hypothesized as the third meta-cognitive determinant of information technology acceptance. Close to social influence $[53,54]$, social connectedness denotes the relationships within and beyond one's social circles. For older adults, interpersonal and community social connectedness contribute to successful aging [55]. The existing literature suggests that the use of information technology has increased knowledge, decreased isolation, generated closer family ties, and contributed to improved connection to society for older adults [56,57]. The longitudinal study of Francis et al. [58] revealed that ICT use, through the promotion of social connectedness, has a significant and positive relationship with mattering, thus indicating its promise to help older adults maintain their sense of community and social connectedness through learning to use information technology [12,57]. In this regard, social connectedness should also be regarded as a profound outcome of using digital devices. Thus, the following hypothesis is proposed:

Hypothesis 5 (H5). The feeling of social connectedness of older adults when using technology will be improved after observational training.

\subsection{Model Identity}

Prior studies have identified the need to study the moderators of the relationship between behavior modeling and training outcomes [59]. Training environments are always critical for examining expected training outcomes [60]. When considering the training environment for older learners, human elements, such as behavior models, instructors, and learning peers, are worth considering. The most frequently reported categories of people preferred for conducting training were older adults themselves, family and peers, and domain professionals [21]. Some studies have suggested that older adults experience difficulty when receiving technical support from young people, and that they learn better when helped by their peers, probably because their peers understand the problems that come with age and have experienced similar problems $[61,62]$. The better the agreement between the model and learner, the greater the chances of improving training outcomes. However, certain studies have recommended facilitation from younger generations such as children and grandchildren. Fausset et al. [63] suggested that the children of older adults play a major role in influencing aspects of their technology adoption and use. A recent study suggested that older adults easily adopt their grandchildren's enthusiasm, which may eventually lighten the burden on their children [64]. Lin et al. [65] noted that older adults chose younger children and friends with skills that they admired as their behavior models in learning to use the Internet. Ruiz-Montero et al. [66] found that experiences of intergenerational service learning 
may increase feelings of social engagement and successful aging in older adults. An investigation and differentiation of older adult learning models from both peers (e.g., neighbors, friends, and relatives) and children is needed to understand which models are more likely to influence their technology use [65]. Therefore, the effectiveness of different behavior models from the generational perspective (e.g., children, young adults, and older adults) in observational training to enhance the digital literacy and technology acceptance of older adults has emerged as an interesting research area. This issue can be stated as the effects of model identity in observational training for older adults, and this study investigates its effect from a generational perspective. Thus, the following hypothesis is proposed:

Hypothesis 6 (H6). Model identity from a generational perspective (child, young adult, and older adult model) will affect the effectiveness of observational training.

\section{Research Design}

\subsection{Method and Procedure}

This study implemented an empirical experiment of observational training through behavior modeling. Using behavior change techniques as a basis $[67,68]$, features such as specific training goals, free practices, performance tasks, proper time-pacing, and comprehensible knowledge were employed in designing the training programs in this study. Recent developments in information and communication technology have steadily extended its societal reach and made it an integral part of the lives of users. Given the increasingly integrated mobile platforms, smartphones and other mobile devices are supplementing computers by helping people access the Internet anytime and anywhere. Touch-screen interfaces are especially prevalent in smartphone technologies and tablet computers. Therefore, a tablet computer was used as the target information technology that participants were trained to use in our study. According to a previous survey [69], older adults in Hong Kong mainly use mobile applications (apps) for transportation, entertainment, social communication, and health care/monitoring. Therefore, these four types of mobile apps were included in this training experiment.

Given that this study aimed at examining the effect of model identity from a generational perspective, a between-group design was developed. Three experimental groups of older adult participants were included in this experiment, namely the child model, young adult model, and older adult model groups. Other than different role models, each participant in the three groups received the same training content and procedure. Models in three generations were recruited for video recording, including a child aged 10 , a young adult aged 23 , and an older adult aged 68 , all three models having at least one year of experience using a tablet and relevant apps.

Behavior modeling was conducted through videotaped demonstrations with the three human models. Motivated by the representation theory of effective use, which clarifies the effective use of information systems [70] through emphasizing sensory, physical, and functional affordances, the entire training consisted of three short observation sessions for each participant, wherein the different models (i.e., child, young adult, and older adult) were used. The first session was delivered by demonstrating basic knowledge, including what a tablet is, what it is used for, and how it works with the Internet. This session lasted for $5 \mathrm{~min}$, and the participant was given $5 \mathrm{~min}$ to touch and experience the tablet. The second session was a demonstration about all the hard buttons (i.e., on-off, volume, screen lock, and the home button), the commonly used control gestures (i.e., tap, slide, roll, and zoom), and basic settings (e.g., luminance and $\mathrm{Wi}-\mathrm{Fi}$ ) of the tablet. This session lasted around $8 \mathrm{~min}$. After watching the video, participants were given $10 \mathrm{~min}$ to try the buttons, hand movements, and settings. The third session was a scenario demonstration by the three models of the daily use of four types of apps (i.e., a transportation app, a video player, a communication app, and a health monitoring app). Cotten et al. [3] stated that, when an instructional program extends across multiple days, the trainees should be provided with homework to try on their own in between training sessions. The effectiveness of an instructional program may be enhanced when consideration is given to the 
limitations of the human information processing system, especially when designing programs for older adults. Sharit and Czaja [71] argued for the importance of understanding the constraints where older adults are likely to confront difficulty during the presentation of learning materials. It is critical that older learners receive the proper presentation sequence of learning materials and are given sufficient time to rehearse this material, such that it becomes adequately stored in their long-term memory. Therefore, the training process was conducted using a one-by-one and a hand-by-hand method to support older adults, especially during challenging encounters. The training video clips were timed to be within $15 \mathrm{~min}$, as it was found in our previous study that the preferred duration of video learning of older adults is no more than $15 \mathrm{~min}$. All the experimental materials with words were adjusted to have a large font size. During the training session, each participant had $30 \mathrm{~min}$ to experience the tablet and rehearse the manipulations in the video. There were $2 \mathrm{~min}$ of rest between each two sections.

Before training, each older adult signed a consent form and answered a pre-training questionnaire, which was used to measure their self-efficacy, outcome expectations, and social connectedness of using information technology. Throughout the process, two trainers assisted the participants. The process of video observation was self-paced, and the participants could ask for help at any time. After all the three sessions, participants were required to complete a performance quiz of cognitive knowledge acquisition and a post-training questionnaire survey. The experimental procedure is shown in Figure 1.

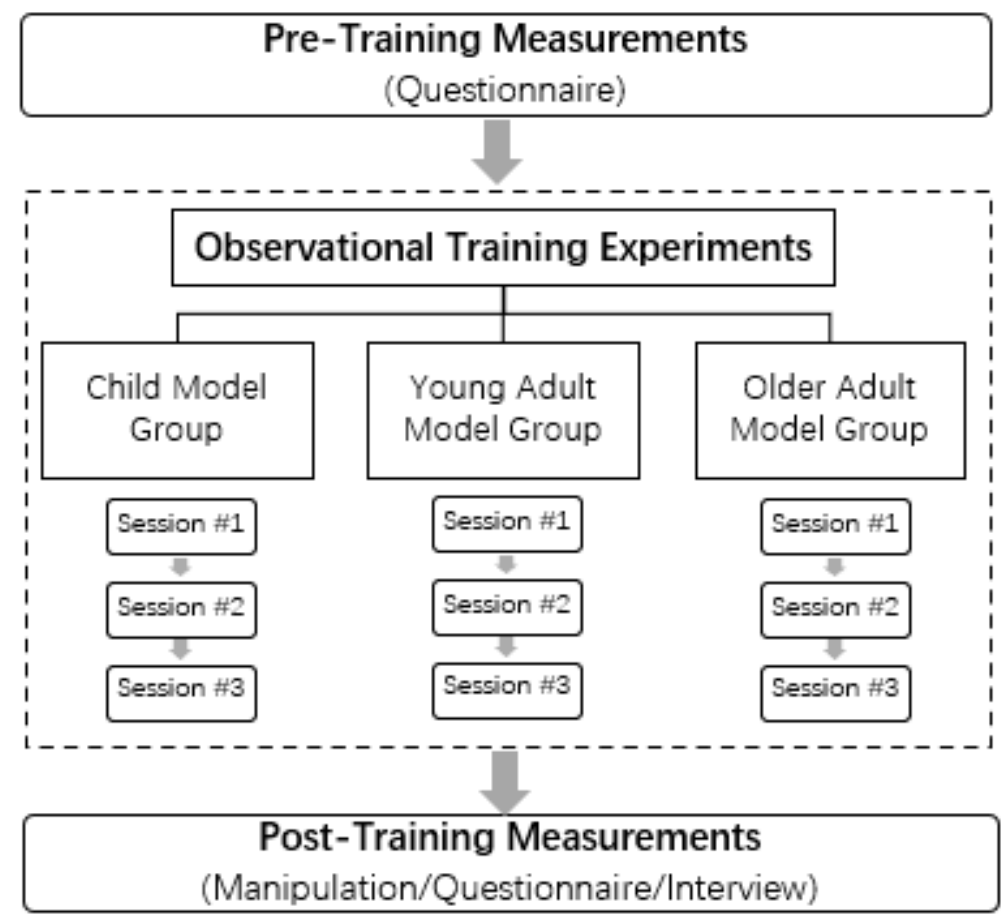

Figure 1. Procedure of observational training experiments.

\subsection{Sampling}

To reduce the heterogeneity of sampling, the criteria for the inclusion of older adult participants were: (1) community-dwelling (i.e., aging-in-place) Chinese older adults in Hong Kong, (2) people aged 60 or older, (3) people with little or no experience (less than 1 week) with using a tablet, and (4) people without severe cognitive impairments. Participants were recruited with the permission and support of a local elderly community service center in Hong Kong. Older adults who were likely to meet these criteria were invited by staff members in the elderly center, given an information letter if they expressed interest in participating, and subsequently called to schedule an appointment. As suggested by the Institutional Review Board (IRB), all participants provided informed consent and their identity was anonymized. Participants had the right to withdraw at any stage of the study without being penalized. 
The experiment was implemented at a local community center, The Salvation Army Chuk Yuen Centre for Senior Citizens, in Hong Kong, with the center's permission and strong support. Eventually, 72 eligible older adults were involved in the experiment. The participants were randomized into three groups: (1) a child model group, (2) a young adult model group, and (3) an older adult model group. Specifically, participant 1 was assigned to the first group, participant 2 was assigned to the second group, and participant 3 was assigned to the third group. The process was repeated until all the participants were assigned. After the experiment, eligible data from 59 participants were retained (21 in the child model group, 19 in the young adult model group, and 19 in the older adult model group); the 13 excluded sets of data were not fully completed due to some unexpected situations during the experiment, including feeling tired (6 participants), scheduling conflicts ( 3 participants), other person's phone call interruption (2 participants), no confidence in completing the whole experiment (1 participants), and physical complaints (1 participants). Demographic information such as age, gender, education, marital status, family members, work status, and economic status were collected through a questionnaire from each participant. For each piece of demographic information, the percentage of every level was calculated in the three experiment groups to ascertain sample bias.

\subsection{Intervention}

Before launching the experiments, the video materials were recorded and edited. Prior to recording, the three models were trained according to a detailed instruction manual about the content they were going to record. The three video models introduced relevant contents using the same script designed by the authors. The gestures in each step were trained to preserve consistency throughout the videos. However, it is not avoidable that there was still a little difference among the three models' demonstrations, as each generation has some idiomatic expressions. The main screen of each video showed the tablet's interface, and there was also a small window in the lower right corner presenting the model's behavior. Screenshots of the videos are shown in Figure 2. Due to the IRB restrictions, the faces and personal information of all the video models are covered and blurred in Figure 2. The videos included a simple introduction of a tablet's physical appearance, buttons, hand gestures, and scenario demonstrations by the three models of the four applications listed above. There were four scenarios simulated in the video: (1) route-planning using the transportation information app, (2) playing a movie with the video player on the tablet and enjoying it, (3) having a conversation with family members using with communication app, and (4) heart rate measurement using the health monitoring app. The same tablet with the four applications installed was used in this study. Although the tablet is not designed or marketed specifically for older adults, its physical and graphical designs, such as its direct input interface and large screen, were deemed appropriate for ease of use among older adults [72].

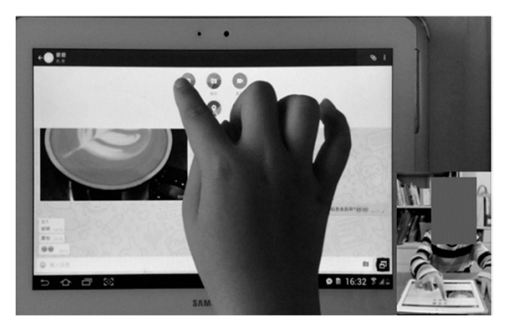

(a)

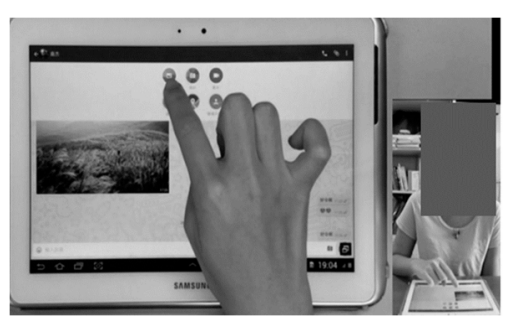

(b)

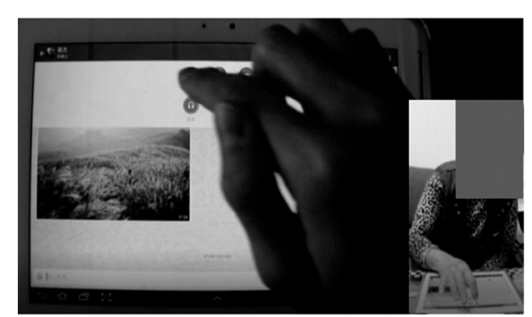

(c)

Figure 2. Screenshots of training videos: (a) shows a child model, (b) shows a young adult model, and (c) shows an older adult model.

\subsection{Measurement Design}

Drawing from research on educational psychology and information systems [40], three different types of training outcomes were measured, including cognitive knowledge acquisition, affective 
responses (i.e., experienced benefits and costs, vicarious incentives, and self-incentives), and meta-cognitive outcomes (i.e., self-efficacy, outcome expectation, and social connectedness). After the training sessions, participants were invited to finish a technical quiz and a post-training questionnaire.

Cognitive knowledge acquisition emphasizes the mental awareness and judgment of the user. The measurement of cognitive knowledge in this study was centered on the basic knowledge of using the tablet through a 10-question multiple choice quiz. Affective goals focus on the emotional aspects of a user's behavior, including motivational knowledge and satisfaction with the training process [42]. Motivational knowledge is the knowledge about what the target product or system can do for the user [42], which was measured through the experienced benefits and costs of participants through learning. Satisfaction with the training process was evaluated through the self-reported vicarious incentive and self-incentive of participants. Finally, meta-cognitive or self-regulated learning knowledge refers to an individual's knowledge regarding their own learning and information processing methods. The most commonly investigated meta-cognitive variable is self-efficacy. Self-efficacy has been shown to be a strong antecedent of intention to use [40]. The computer self-efficacy scale [73] was used to measure that variable. Additionally, motivated by SCT, outcome expectation (OE) was also measured as a meta-cognitive outcome through the scale outlined by Compeau and Higgins [41]. Furthermore, given that an important benefit of the use of these communication technologies is the enhancement of a sense of connectedness, belonging, and relatedness [74,75], a social connectedness (SC) scale [76] was employed as well. The three meta-cognitive variables were also measured in the pre-training questionnaire.

In this study, two intention variables were introduced to provide an in-depth view of the effects of training outcomes on the intention of older adults to use information technology. Behavior intention [77], an indication of individual readiness to perform a given behavior, is an immediate antecedent of behavior. A gerontechnology acceptance scale [37] was utilized to measure the post-training behavior intention of participants to use technology. Another essential component in understanding intention to use is willingness to recommend [78], which measures the percentage of customers who would recommend a product or a service to others. Many organizational leaders consider this metric when predicting future purchasing patterns. Both behavior intention for older adults to adopt technology and willingness to recommend technology to others were hypothesized to be influenced by post-training outcomes. The construct of behavioral intention is well-accepted in technology acceptance research. All variables were measured on a 7-point Likert scale, where " 1 " represented "strongly disagree" and "7" represented "strongly agree". The descriptions of all antecedents that were hypothesized in this study to influence intention of older adults to use technology are presented in Table 1. 
Table 1. Measurements of training outcomes.

\begin{tabular}{|c|c|c|c|c|c|}
\hline Training Goals & Measurement & Definition & References & $\begin{array}{c}\text { Keywords } \\
\text { of Survey Items }\end{array}$ & Scoring Rubric \\
\hline $\begin{array}{l}\text { Cognitive } \\
\text { Knowledge }\end{array}$ & $\begin{array}{l}\text { 10-question } \\
\text { quiz }\end{array}$ & & & & $\begin{array}{c}1 \text { to } 10 \text { marks, } 1 \\
\text { mark for each } \\
\text { correct answer. }\end{array}$ \\
\hline \multirow[t]{4}{*}{$\begin{array}{l}\text { Affective } \\
\text { Response }\end{array}$} & $\begin{array}{l}\text { Experienced } \\
\text { Benefits (EB) }\end{array}$ & $\begin{array}{l}\text { Perceived benefit refers } \\
\text { to the perception of the } \\
\text { positive consequences } \\
\text { that are caused by a } \\
\text { specific action. Here, it } \\
\text { indicates the usefulness } \\
\text { of learning to use } \\
\text { technology they } \\
\text { experienced through the } \\
\text { training. }\end{array}$ & $\begin{array}{l}\text { Sharit, Czaja [79]; } \\
\text { Delello and } \\
\text { McWhorter [57] }\end{array}$ & $\begin{array}{l}\text { Usefulness; } \\
\text { convenience; } \\
\text { happiness. }\end{array}$ & $\begin{array}{c}\text { 7-point } \\
\text { disagree- } \\
\text { agree rubric. }\end{array}$ \\
\hline & $\begin{array}{l}\text { Experienced } \\
\text { Costs (EC) }\end{array}$ & $\begin{array}{l}\text { Costs are resources } \\
\text { invested including } \\
\text { monetary costs, time } \\
\text { costs, and cognitive costs } \\
\text { regarding learning to use } \\
\text { and adopt technology } \\
\text { through the training. }\end{array}$ & $\begin{array}{l}\text { Sharit, Czaja [79]; } \\
\text { Ma, Chan [80] }\end{array}$ & $\begin{array}{l}\text { Cost of money; } \\
\text { cost of learning } \\
\text { efforts; cost of } \\
\text { time. }\end{array}$ & $\begin{array}{l}\text { 7-point } \\
\text { disagree- } \\
\text { agree rubric. }\end{array}$ \\
\hline & $\begin{array}{c}\text { Vicarious } \\
\text { Incentive (VI) }\end{array}$ & $\begin{array}{l}\text { Adapted from SCT, it is } \\
\text { the observation of } \\
\text { rewards and } \\
\text { punishments that others } \\
\text { receive by performing a } \\
\text { behavior. }\end{array}$ & $\begin{array}{l}\text { Bandura [81]; } \\
\text { Ebbers [82] }\end{array}$ & $\begin{array}{l}\text { Easy to use; } \\
\text { brings benefits; } \\
\text { it is popular; } \\
\text { it's a smart } \\
\text { decision. }\end{array}$ & $\begin{array}{c}\text { 7-point } \\
\text { disagree- } \\
\text { agree rubric. }\end{array}$ \\
\hline & $\begin{array}{l}\text { Self-Incentive } \\
\text { (SI) }\end{array}$ & $\begin{array}{c}\text { Self-produced incentive } \\
\text { is set by the individual } \\
\text { for performing a } \\
\text { behavior; it is the degree } \\
\text { to which a } \\
\text { product/service gives the } \\
\text { user satisfaction with his } \\
\text { or her achievements. }\end{array}$ & $\begin{array}{l}\text { Bandura [81]; } \\
\text { Park [83] }\end{array}$ & $\begin{array}{l}\text { Satisfactory; } \\
\text { confident; } \\
\text { Personal } \\
\text { growth; } \\
\text { Self-fulfillment. }\end{array}$ & $\begin{array}{c}\text { 7-point } \\
\text { disagree- } \\
\text { agree rubric. }\end{array}$ \\
\hline \multirow[t]{3}{*}{$\begin{array}{l}\text { Meta-cognitive } \\
\text { Outcomes }\end{array}$} & $\begin{array}{l}\text { Self-Efficacy } \\
\quad \text { (SE) }\end{array}$ & $\begin{array}{l}\text { Self-efficacy is the belief } \\
\text { that individual } \\
\text { performance will match } \\
\text { all pertinent } \\
\text { performance standards } \\
\text { for a given behavior. }\end{array}$ & $\begin{array}{c}\text { Venkatesh, Morris } \\
\text { [84]; } \\
\text { Murphy, Coover } \\
\text { [73]; } \\
\text { Chen \& Chan [37] }\end{array}$ & $\begin{array}{l}\text { I am able to use; } \\
\text { I am able to } \\
\text { complete tasks; } \\
\text { I am able to } \\
\text { solve problems. }\end{array}$ & $\begin{array}{c}\text { 7-point } \\
\text { disagree- } \\
\text { agree rubric. }\end{array}$ \\
\hline & $\begin{array}{l}\text { Outcome } \\
\text { Expectation } \\
\text { (OE) }\end{array}$ & $\begin{array}{l}\text { Outcome expectation is } \\
\text { the probabilistic belief a } \\
\text { person holds that a given } \\
\text { outcome will be brought } \\
\text { about through the } \\
\text { engagement in a specific } \\
\text { behavior. }\end{array}$ & $\begin{array}{c}\text { Compeau and } \\
\text { Higgins [39]; } \\
\text { Venkatesh, Morris } \\
\text { [84] }\end{array}$ & $\begin{array}{l}\text { Useful in daily } \\
\text { life; become } \\
\text { independent; } \\
\text { increase quality } \\
\text { of life; improve } \\
\text { efficiency. }\end{array}$ & $\begin{array}{c}\text { 7-point } \\
\text { disagree- } \\
\text { agree rubric. }\end{array}$ \\
\hline & $\begin{array}{c}\text { Social } \\
\text { Connectedness } \\
\text { (SC) }\end{array}$ & $\begin{array}{l}\text { Social connectedness is } \\
\text { an attribute of the self } \\
\text { that reflects cognitions of } \\
\text { enduring interpersonal } \\
\text { closeness with the social } \\
\text { world. }\end{array}$ & $\begin{array}{c}\text { Lee [76]; } \\
\text { Lee \& Robbins [85] }\end{array}$ & $\begin{array}{l}\text { Feel close to } \\
\text { people; feel } \\
\text { social inclusion; } \\
\text { able to connect } \\
\text { with others; } \\
\text { feel in tune } \\
\text { with the world. }\end{array}$ & $\begin{array}{l}\text { 7-point } \\
\text { disagree- } \\
\text { agree rubric. }\end{array}$ \\
\hline
\end{tabular}

\subsection{Analytical Approaches}

First, the reliability and validity of all measurements were examined by computing composite reliability, factor loadings, and average variance extracted values. Next, the demographic information of the older adults in each experiment group was classified and calculated to ascertain sample biases among the three groups. A descriptive analysis of training outcomes was developed, including the 
minimum, maximum, and average values, as well as the standard deviation. In order to compare variations of the meta-cognitive outcomes before and after the training experiment, a paired $t$-test was developed, which is a statistical test that compares the averages and standard deviations of two related or same groups to determine if there is a significant difference. Additionally, as model identity was assumed to be an important element affecting training outcomes, a between-group comparison of cognitive knowledge, affective responses, and meta-cognitive outcomes was developed using a multiple factor ANOVA test. The ANOVA results can help to assess whether there are differences in how older adults perceive the video across the different video models. Finally, in order to dive deeper into the differences examined through the ANOVA test, this study employed a post-hoc test to ascertain the differences of pairwise comparisons.

\section{Results}

\subsection{Measurement Evaluation}

A pretest of the experiment was conducted with two aging research experts and four older adults to check the content validity, following which minor re-wording was made; specifically, the phrase "personal development" was changed to "personal growth", options of "living arrangement" were adjusted, and the phrase "older adults" was deleted throughout the questionnaire and instructions. Overall, the reliability and validity of all measurements were evaluated. The Kaiser-Meyer-Olkin test result was $0.75(>0.6)$ and Bartlett's test was significant, indicating that the sampling was satisfactory to conduct factor analysis. Principal component analysis and varimax rotation were used to calculate factor loadings. The factor loadings of all factors were higher than the threshold criteria of 0.5 . Convergent validity, which represents the correspondence or convergence between similar constructs, is judged to be acceptable if factor loading estimates and average variance extracted values are higher than 0.5 [86]. The average variance extracted values of all constructs were higher than 0.5 . To test the internal consistency and reliability of the measurements, composite reliability was examined. The composite reliability values of all constructs were higher than the criterion of 0.6. Therefore, the measurements in this study were considered valid and reliable for further data analyses.

\subsection{Demographic Information}

Demographic information (e.g., age, gender, education, marital status) was collected from all eligible participants. Table 2 shows the summary of demographic characteristics of the 59 participants. In summary, all participants were aged 60 and above, and more than $70 \%$ of them were aged 70 and above. Female participants outnumbered the males, as female older adults are typically more active in participating in such activities. Most participants only had primary education (44.1\%) or high school education $(42.4 \%)$. Half of the married older adults were currently single as they were either divorced or widowed. All of them were retired. Most of them reported an average level of their economic status, and no one thought of themselves as rich. Over half of the participants had a spouse accompanying them. A total of $73 \%$ of them had children, and nearly half of them had grandchildren. When looking at the demographic information between groups, no obvious bias was found in the three training groups. 
Table 2. Demographic information.

\begin{tabular}{|c|c|c|c|c|c|}
\hline Demographics & & $\begin{array}{c}\% \\
\text { All }\end{array}$ & $\begin{array}{c}\% \\
\text { Child Model } \\
\text { Group }\end{array}$ & $\begin{array}{c}\% \\
\text { Young Model } \\
\text { Group }\end{array}$ & $\begin{array}{c}\% \\
\text { Older Model } \\
\text { Group }\end{array}$ \\
\hline \multirow[t]{6}{*}{ Age } & $60-64$ & 8.5 & 9.5 & 5.3 & 10.5 \\
\hline & $65-69$ & 16.9 & 19.05 & 15.8 & 15.8 \\
\hline & $70-74$ & 23.7 & 23.8 & 26.3 & 21.1 \\
\hline & $75-79$ & 27.1 & 28.6 & 26.3 & 26.3 \\
\hline & $80-85$ & 22.1 & 19.05 & 21.1 & 26.3 \\
\hline & $>85$ & 1.7 & 0 & 5.2 & 0 \\
\hline \multirow[t]{2}{*}{ Gender } & Female & 67.8 & 66.7 & 73.7 & 63.2 \\
\hline & Male & 32.2 & 33.3 & 26.3 & 36.8 \\
\hline \multirow[t]{4}{*}{ Education } & College & 10.1 & 9.5 & 10.5 & 10.5 \\
\hline & High School & 42.4 & 38.1 & 47.4 & 42.1 \\
\hline & Primary & 44.1 & 52.4 & 36.8 & 42.1 \\
\hline & Informal & 3.4 & 0 & 5.3 & 5.3 \\
\hline \multirow[t]{2}{*}{ Marital Status } & Married & 52.5 & 61.9 & 52.6 & 52.6 \\
\hline & Single & 47.5 & 38.1 & 47.4 & 47.4 \\
\hline Working Status & Retired & 100 & 100 & 100 & 100 \\
\hline \multirow[t]{3}{*}{ Economic Status } & Poor & 11.9 & 9.5 & 10.5 & 15.8 \\
\hline & General & 84.7 & 90.5 & 79 & 84.2 \\
\hline & Very Poor & 3.4 & 0 & 10.5 & 0 \\
\hline \multirow[t]{2}{*}{ Have a Spouse } & No & 47.5 & 57.1 & 36.8 & 47.4 \\
\hline & Yes & 52.5 & 42.9 & 63.2 & 52.6 \\
\hline \multirow[t]{2}{*}{ Have Children } & No & 27.1 & 33.3 & 31.6 & 15.8 \\
\hline & Yes & 72.9 & 66.7 & 68.4 & 84.2 \\
\hline \multirow[t]{2}{*}{$\begin{array}{l}\text { Have } \\
\text { Grandchildren }\end{array}$} & No & 55.9 & 66.7 & 42.1 & 57.9 \\
\hline & Yes & 44.1 & 33.3 & 57.9 & 42.1 \\
\hline \multirow[t]{2}{*}{ Alone } & No & 86.4 & 85.7 & 84.2 & 89.5 \\
\hline & Yes & 13.6 & 14.3 & 15.8 & 10.5 \\
\hline
\end{tabular}

\subsection{Descriptive Results of Training Outcomes}

Table 3 shows the training outcomes, including the quiz scores of cognitive knowledge, affective responses, meta-cognitive outcomes, and intention variables. A 7-point Likert scale was used to measure the affective responses of participants after obtaining the training and meta-cognitive outcomes of pre- and post-training. The average quiz score of cognitive knowledge was 5.712 with a minimum score of 2 and a maximum score of 9 (10 marks in total). The mean score of affective responses was 5.529 , and the mean and minimum scores of vicarious incentives were the highest among the affective responses. The average self-reported scores of pre- and post-meta-cognitive outcomes were 4.688 and 5.312 , respectively. Specifically, the scores for self-efficacy in pre- and post-trainings were the lowest among the meta-cognitive outcomes. The mean of intention variables, including behavioral intention and recommendation willingness, was 5.532, which indicated the positive technology usage intention of participants after training. 
Table 3. Descriptive results of training outcomes.

\begin{tabular}{|c|c|c|c|c|}
\hline & Minimum & Maximum & Mean & Std. Deviation \\
\hline \multicolumn{5}{|l|}{ Affective Response } \\
\hline VI & 4 & 7 & 5.864 & 0.532 \\
\hline SI & 1 & 7 & 5.364 & 1.150 \\
\hline $\mathrm{EB}$ & 2 & 7 & 5.394 & 0.860 \\
\hline EC & 3 & 7 & 5.492 & 0.962 \\
\hline Mean & & & 5.529 & \\
\hline \multicolumn{5}{|l|}{ Meta-Cognitive } \\
\hline SE_Pre & 1 & 7 & 3.053 & 1.667 \\
\hline OE_Pre & 2 & 7 & 5.458 & 1.043 \\
\hline SC_Pre & 2 & 7 & 5.554 & 0.888 \\
\hline Pre-Mean & & & 4.688 & \\
\hline SE_Post & 1 & 7 & 4.288 & 1.682 \\
\hline OE_Post & 1 & 7 & 5.813 & 0.963 \\
\hline SC_Post & 3 & 7 & 5.836 & 0.720 \\
\hline Post-Mean & & & 5.312 & \\
\hline \multicolumn{5}{|l|}{ Intention } \\
\hline BI & 2 & 7 & 5.674 & 1.022 \\
\hline RW & 2 & 7 & 5.390 & 1.126 \\
\hline Mean & & & 5.532 & \\
\hline
\end{tabular}

Note: $\mathrm{VI}=$ vicarious incentive; $\mathrm{SI}$ = self-incentive; $\mathrm{EB}=$ experienced benefits; $\mathrm{EC}=$ experienced costs; $\mathrm{SE}=$ self-efficacy; $\mathrm{OE}=$ outcome expectation; $\mathrm{SC}=$ social connectedness; $\mathrm{BI}=$ behavioral intention; $\mathrm{RW}=$ recommendation willingness; " 1 " indicates "strongly disagree"; " 2 " indicates "disagree"; " 3 " indicates "somewhat disagree"; " 4 " indicates "neutral"; " 5 " indicates "somewhat agree"; 6 indicates "agree"; "7" indicates "strongly disagree".

\subsection{Pre- and Post-Training Comparisons of Three Meta-Cognitive Outcomes}

The effectiveness of the training was measured through the comparisons of meta-cognitive responses (i.e., self-efficacy, outcome expectation, and social connectedness) in the pre- and post-training stages. A paired t-test was employed for the comparisons. Table 4 exhibits the test results of the comparisons of the whole sample, child model group, young adult model group, and older adults model group. All scores for the three factors significantly increased after the observational training experiment, considering the entire sample (see Table 4). Thus, Hypotheses 3-5 were supported. Figure 3 shows that self-efficacy increased more, compared with the other two factors, after the training. Comparing the scores of the three meta-cognitive outcomes of the child model group, this study found that only self-efficacy significantly increased $(p<0.001)$ after training (see Table 4$)$. Social connectedness and outcome expectation also improved, but not at a significant level $(p>0.05)$. In the young adult model group, again, only self-efficacy significantly increased after the training. Similar to the results in the child model group, social connectedness and outcome expectation improved slightly, but not at a significant level $(p>0.05)$. In the older adult model group, both self-efficacy and social connectedness significantly increased after training. Outcome expectation improved, but not at a significant level $(p>0.05)$. Overall, when the moderating effects of models were ignored, the scores of all three variables improved significantly. However, the results changed when considering the differences of the nature of the three models. Self-efficacy significantly improved, whatever the model type, while outcome expectation did not significantly improve. The score of social connectedness significantly increased only in the older adult model group. The insignificant results, in terms of the improvements of social connectedness in both child and young adult group, may be attributed to the generation identity of older adults; that is, they may experience difficulty when receiving technical support from young people [61]. Instead, older adults in training feel more connected with others when communicating with their peers. The outcome expectation after this training did not increase in all three groups. With technical evolution and the prevalence of emerging information and communication technologies, older adults may have seen the benefits of these devices under the influence of important peers. 
Table 4. Paired t-test of self-efficacy, outcome expectation, and social connectedness before and after training.

\begin{tabular}{ccccccc}
\hline Meta-Cognitive Responses & $\begin{array}{c}\text { Mean } \\
\text { (Pre-Post) }\end{array}$ & $\begin{array}{c}\text { Std. } \\
\text { Deviation }\end{array}$ & $\begin{array}{c}\text { 95\% CI } \\
\text { Lower }\end{array}$ & $\begin{array}{c}\text { 95\% CI } \\
\text { Upper }\end{array}$ & $t$ & $p$-Value \\
\hline Whole Sample (Sample Size = 59) & & & & & & \\
\hline SE & -1.922 & 1.640 & -2.350 & -1.495 & -9.002 & 0.000 \\
OE & -0.356 & 0.954 & -0.605 & -0.107 & -2.866 & 0.006 \\
SC & -0.344 & 0.934 & -0.587 & -0.101 & -2.830 & 0.006 \\
\hline Child Model (Sample Size = 21) & & & & & & \\
\hline SE & -1.595 & 1.729 & -2.382 & -0.808 & -4.227 & 0.000 \\
OE & -0.286 & 0.681 & -0.596 & 0.0245 & -1.922 & 0.069 \\
SC & -0.134 & 0.930 & -0.557 & 0.290 & -0.660 & 0.517 \\
\hline Young Adult Model (Sample Size $=19)$ & & & & & \\
\hline SE & -1.890 & 1.341 & -2.536 & -1.243 & -6.142 & 0.000 \\
OE & -0.408 & 1.197 & -0.985 & 0.169 & -1.486 & 0.155 \\
SC & -0.237 & 0.742 & -0.595 & 0.1209 & -1.391 & 0.181 \\
\hline Older Adult Model (Sample Size $=19)$ & & & & & 0.000 \\
\hline SE & -2.316 & 1.804 & -3.185 & -1.446 & -5.594 & 0.109 \\
OE & -0.382 & 0.987 & -0.857 & 0.094 & -1.685 & 0.011 \\
\hline SC & -0.684 & 1.055 & -1.192 & -0.175 & -2.826 &
\end{tabular}

Note: $\mathrm{SE}=$ self-efficacy $; \mathrm{OE}=$ outcome expectation; $\mathrm{SC}=$ social connectedness.

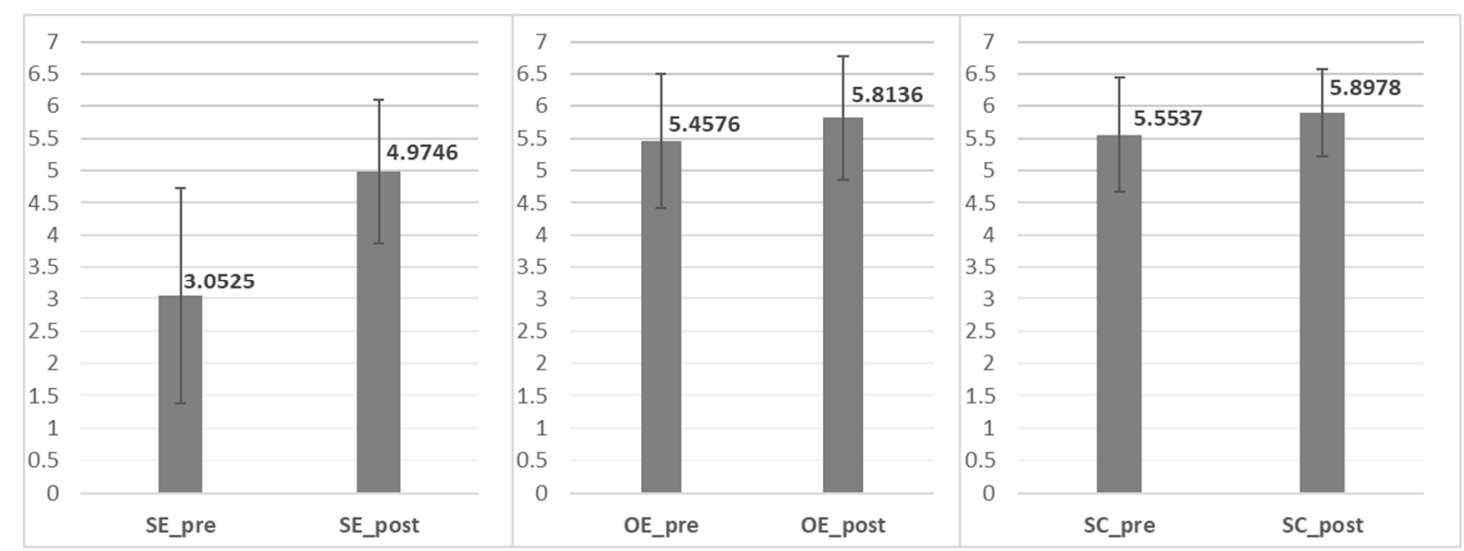

Figure 3. Comparison of self-efficacy, outcome expectation, and social connectedness preand post-training.

\subsection{Between-Group Comparisons of Cognitive Knowledge, Affective Responses, and Meta-Cognitive Outcomes}

Model identity was set as a possible moderator affecting the observational training effectiveness. The three models were hypothesized, resulting in different degrees of behavioral changes. An ANOVA test was employed in this study to examine the effects of model identity on observational training outcomes, including cognitive quiz scores, affective and meta-cognitive scores, and final usage intention. Table 5 summarizes the significance results of the ANOVA test. Among these outcomes, self-efficacy improvement after training was significantly different among the three groups $(F=3.878$; $p<0.05)$. In addition, recommendation willingness after training was also significantly different across the three groups $(F=6.031 ; p<0.01)$. The average cognitive quiz score was $5.712(S D=1.829)$ for the 59 participants, which means that their accuracy rate in the 10 questions was near $60 \%$. However, the ANOVA test shows that no significant difference emerged with respect to the cognitive knowledge quiz scores of the participants across the three training groups $(F=0.029 ; p>0.05)$. The 
insignificant result, in terms of the knowledge quiz, may be attributed to the standardized instructions and manipulation steps in each training video, as well as the design of the structured digital literacy questions. Furthermore, the affective training outcomes of experienced benefits and costs, vicarious incentive, and self-incentive scores were not significantly different among the three groups. These results may be explained by human information processing [71]. These direct and one-off outputs from the observational training did not show any difference in short-term memory of older adults. They are expected to have some differences when a longitudinal study could be developed, as long-term memory might be built after continuous training. Therefore, H3 was partially supported.

Table 5. The effects of different models (child, young adult, and older adult) on observational training outcomes: ANOVA test results.

\begin{tabular}{|c|c|c|c|c|c|c|}
\hline Variables & & $\begin{array}{l}\text { Sum of } \\
\text { Squares }\end{array}$ & $d f$ & $\begin{array}{l}\text { Mean } \\
\text { Square }\end{array}$ & $F$ & $p$-Value \\
\hline \multirow{2}{*}{$\begin{array}{l}\text { Self-Efficacy } \\
\text { Improvement }\end{array}$} & $\begin{array}{l}\text { Between } \\
\text { Groups }\end{array}$ & 30.634 & 2 & 15.317 & \multirow[t]{2}{*}{3.878} & \multirow[t]{2}{*}{0.026} \\
\hline & $\begin{array}{l}\text { Within } \\
\text { Groups }\end{array}$ & 221.163 & 56 & 3.949 & & \\
\hline \multirow{4}{*}{$\begin{array}{l}\text { Recommendation } \\
\text { Willingness }\end{array}$} & Total & 251.797 & 58 & & \multirow{4}{*}{6.031} & \multirow{4}{*}{0.004} \\
\hline & $\begin{array}{l}\text { Between } \\
\text { Groups }\end{array}$ & 18.101 & 2 & 9.05 & & \\
\hline & Within & 84.035 & 56 & 1.501 & & \\
\hline & Total & 102.136 & 58 & & & \\
\hline
\end{tabular}

To obtain information on the differences examined through the ANOVA test, this study employed a post-hoc test (LSD). Table 6 shows the results. In terms of self-efficacy improvement, the older adult model group contributed to the highest improvement, and no significant difference between the child model group and the young adult model group emerged. As for recommendation willingness, no significant difference was found between the child model group and the older adult model group; however, both groups were significantly better, when compared with the young adult model group $(p<0.05)$.

Table 6. Post hoc test of self-efficacy improvement and recommendation willingness among the three groups (LSD).

\begin{tabular}{|c|c|c|c|c|c|c|}
\hline Dependent Variable & $\begin{array}{c}\text { (I) } \\
\text { Model }\end{array}$ & $\begin{array}{c}(\mathrm{J}) \\
\text { Model }\end{array}$ & $\begin{array}{l}\text { Mean Difference } \\
\text { (I-J) }\end{array}$ & $\begin{array}{l}\text { Std. } \\
\text { Error }\end{array}$ & $\begin{array}{l}95 \% \text { CI } \\
\text { Lower }\end{array}$ & $\begin{array}{l}95 \% \text { CI } \\
\text { Upper }\end{array}$ \\
\hline \multirow{6}{*}{$\begin{array}{l}\text { Self-Efficacy } \\
\text { Improvement }\end{array}$} & Child & Young & 0.486 & 0.629 & -0.774 & 1.747 \\
\hline & & Old & -1.251 & 0.629 & -2.511 & 0.01 \\
\hline & Young & Child & -0.486 & 0.629 & -1.747 & 0.774 \\
\hline & & Old & $-1.737 *$ & 0.645 & -3.029 & -0.445 \\
\hline & Old & Child & 1.251 & 0.629 & -0.01 & 2.511 \\
\hline & & Young & 1.737 * & 0.645 & 0.445 & 3.029 \\
\hline \multirow{6}{*}{$\begin{array}{l}\text { Recommendation } \\
\text { Willingness }\end{array}$} & Child & Young & $1.246^{*}$ & 0.388 & 0.469 & 2.023 \\
\hline & & Old & 0.140 & 0.388 & -0.637 & 0.917 \\
\hline & Young & Child & $-1.246^{*}$ & 0.388 & -2.023 & -0.469 \\
\hline & & Old & $-1.105 *$ & 0.397 & -1.901 & -0.309 \\
\hline & Old & Child & -0.140 & 0.388 & -0.917 & 0.637 \\
\hline & & Young & $1.105 *$ & 0.397 & 0.309 & 1.901 \\
\hline
\end{tabular}




\section{Discussion}

The importance and growth of information technology training makes it an ideal context to study the effect of training methods [42] and to encourage technology adoption among older adults. Technology training has been widely recognized as an essential contributor to the productive use of technologies. However, little research has focused on identifying the processes through which training operates and on training methods for intervening in technology adoption by older adults. Therefore, this study investigated the effectiveness of observational learning through behavior modeling in enhancing the intention of information technology use in older adults via empirical experiments. In particular, the moderating effects of model identity on training outcomes were examined. One of the key contributions of this study is a practical illustration of distinguishing the effects of different behavior models on technology training outcomes of older adults from a generational perspective. The findings of this study are structured and presented in Figure 4.

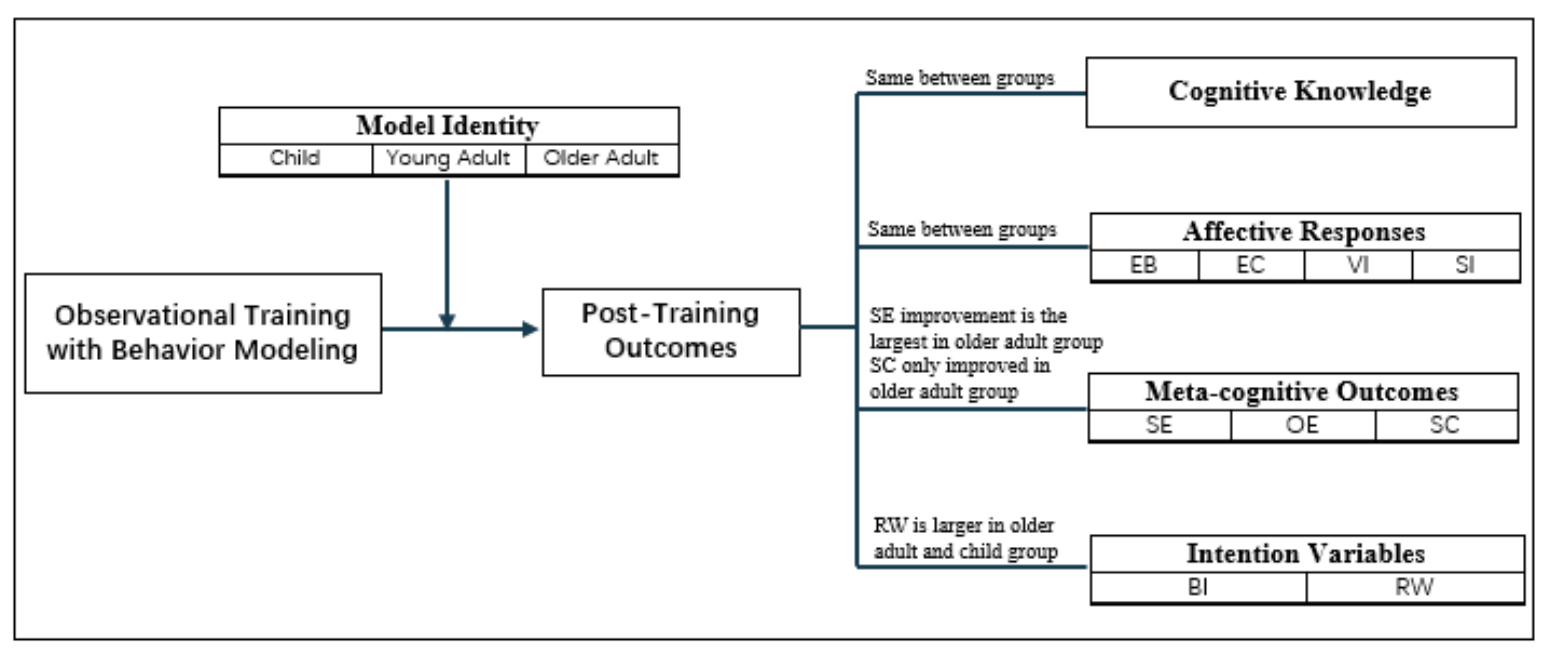

Figure 4. Structured findings after observational training experiments for self-efficacy (SE), outcome expectations (OE), social connectedness (SC), observed benefits (OB), observed costs (OC), vicarious incentives (VI), self-incentives (SI), behavioral intention (BI), and recommendation willingness (RW).

\subsection{Current Use of Mobile Devices}

This study was implemented through empirical one-off training experiments. All participants were retired Hong Kong older adults with low-to-average economic status. Most of them were smartphone users, which indicated that smartphones were gradually becoming a necessity for them. However, less than $40 \%$ of these participants were using the Internet frequently due to limited access to and knowledge of the Internet. Apart from making phone calls and sending messages, most of them have not benefited much from mobile devices and applications to present. These results are in agreement with a prior study that older adults in Hong Kong continue to lack sufficient experience and knowledge to fully utilize mobile devices such as smartphones and tablets [87].

When technology adoption was considered, most older adults indicated that they do not have the common route of exposure that most people in the younger population experienced, such as in the workplace or through an educational setting. This circumstance may be a key factor for low acquisition among older adults. When an intention to learn comes to light, the exploration of possibilities is initiated to acquire, purchase (or borrow-e.g., from a relative), and experiment with the technology [26]. Most older adults will watch friends or family members using the technology and learn from them. Exploring and experimenting with an information technology device gives an older user a realistic picture of how difficult learning is. Therefore, providing appropriate technology training is necessary for older adults to touch and play around the innovative technologies, to improve 
their skills and broaden their knowledge and experiences and, more importantly, to enhance their confidence and willingness to accept new technologies.

\subsection{Effectiveness of Observational Training}

When conceptualized with multiple learning outcomes, the findings from this study indicate that participants did, in fact, benefit from the observational training through the behavior modeling method. After touching and experimenting with tablet computers through observational training, the older adults in this study expressed their willingness to learn and use the devices, which supported similar findings of a past study [19].

The participant's quiz results of cognitive knowledge acquisition corroborated the initial finding as they scored nearly $60 \%$ (average) of answers correct for the cognitive quiz after the one-off training, which was better than knowing nothing before the training. Compared with a prior study which used video to train young participants with an end-user software and scored a $70 \%$ correct rate of final cognitive knowledge acquisition after one month training [42], the quiz scores of the older adult participants gained in this training study were satisfactory.

The scores of all four affective responses reported after the training were higher than " 5 " on the 7-point scale, where " 5 " indicated "somewhat agree"; the score of vicarious incentive was the highest. Through observational learning, the recipients were expected to receive strong vicarious reinforcements and incentives, as supported by SCT [38]. During the interview in the post-training stage, the older adults in this study expressed that their sense of social connectedness from using the tablet motivated them to have more interest in learning to use the technology, and that they felt closely connected with others. Self-incentive, similar to self-satisfaction, is a critical affective outcome of technology training [40]. The results showed that older adults with higher degree of self-incentive or self-satisfaction after the training would have more positive expectations of their technology outcomes. This result, although not examined with regression analysis, was consistent with prior studies of the positive effects of self-satisfaction on perceived ease of use and usefulness of information technology $[80,83]$. One essential objective of the technology training is to help older adults to understand the benefits of learning to use technologies. The older adults could observe the benefits of using tablets for communication, transportation, health, and entertainment during the training. Through their own observations, they saw that the tablets looked easy to use and had great potential for personal benefits. Consistent with a prior study, older adults in this study gained positive expected outcomes (i.e., had high perceived usefulness) about using tablet computers by observing others [12]. Moreover, the experienced costs in this study referred to monetary and effort costs. In a previous cross-sectional survey, cost has been singled as a negative predictor of the intention of using smartphones [80]. In a similar but not identical way, experienced costs in this study was found as a negative predictor of outcome expectations instead of a direct predictor of behavior intention for using technologies. Training could partially account for this difference, which weakened the direct negative effects of costs on the intention of older adults in using technologies. During the observational training, apart from experienced benefits, the older adults focused on the costs and frequently asked questions or made comments like "How much is the data service plan?", "Is it free to download applications?", and "Every time I download a new application, I need to learn how to use it." Although a previous study has verified that older adults care more about benefits than costs when attempting to adopt a technological device [79], this study suggests to not ignore the importance of experienced costs in bridging the digital divide. The aspect of cost needs attention in future digital divide research and practices for older adults.

Meta-cognitive outcomes, including self-efficacy, outcome expectations toward technology, and the sense of social connectedness, were significantly increased prior to and after the training. The results show that self-efficacy increased more after the training, compared with the other two meta-cognitive outcomes, which is interesting. The improvement of self-efficacy through training agreed with a prior study, which focused on young adults in end-user training [42]. Many information systems studies 
have focused on developing positive outcome expectations toward information technologies, systems, and software $[39,88]$. The outcome expectations of the participants also improved in this study. After observing the performances of the models in the video, the participants became convinced that using tablets would be beneficial in their lives. Older adults in this study had strong expectations on the outcomes of social communication and catching the social trend by using tablets, due to the strong vicarious reinforcement during observational learning. Moreover, through observing the models to communicate with their families and friends and conducting self-experiments using tablets, these older adults felt a strong sense of social connectedness. Two of the most obvious benefits of information technology for individuals are communication and building social networks, whereby older adults expect to reduce the feeling of isolation with the use of information technology devices [89]. In prior studies of information technology and end-user training, enhancing or reinforcing the sense of social connectedness through technology use has often been neglected. Nevertheless, one prior study affirmed that elderly users may recommend tablets to others [12]. Indeed, social connectedness plays an important role in predicting the willingness of an older adult to recommend information technology to others, such as their friends and families, indicating that social influence between older adults and their peers is bidirectional. Today, many older adults experience increasing appreciation of technology due to positive conversations with families, friends, and professional caregivers [90]. The need to maintain social connectedness has a great effect on their behavior, especially during the initial stages of technology adoption $[36,91]$. Even with a limited time of learning, through watching video modeling and concise demonstration, the older adults in this study improved their knowledge and positive meta-cognitions of using a specific technology product. Training with high levels of structured learning dimensions thus positively affects the enhancement of technology adoption in older adults.

\subsection{Effects of Model Identity}

This study also opens the black box of model identity not studied by earlier researchers. In particular, the moderating effects of model identity in observational learning through behavior modeling were supported in this training experiment. In agreement with the referent informational influence theory, which encapsulates the social influence process with identification-contingent conformity, indicating that people tend to seek identity-consistent behavior to those who are generally considered to be prototypical of their cohort [92,93], the older adult model in this study was identified as the most effective model in improving the intention of using technologies in participants. Kadylak et al. [94] found that the mobile phone behavior displayed by younger family members during face-to-face interactions breached the expectations of older adults regarding appropriate etiquette and manners. The perspectives that older adults often rely on peers for validation of behaviors, including purchase and use of technology [95], and that they are more susceptible to their friends and surrounding environment [96], also support our findings.

In addition, self-efficacy improvement and recommendation willingness were significantly different across the three training groups. In the child model group and the young adult model group, only self-efficacy significantly increased $(p<0.001)$ after training; whereas, in the older adult model group, self-efficacy and social connectedness significantly increased after training. In particular, the older adult model group contributed to the highest improvement of self-efficacy improvement, and no significant difference between the child model group and the young adult model group was found. The main reason for this is that, in sharp contrast to young people, older adults share similar learning experiences and abilities [62]. As for recommendation willingness, the older adult model and child model groups were significantly better than the young adult model group, while no difference was found between the child model group and the older adult model group. The peer model could provide additional conformed information of using a technological device to older adults, and thus, they would recommend this model to their peers. A possible reason explaining the excellence of the child model in arousing recommendation willingness is that the older adults always spend much affection on their grandchildren [97] and they may feel a sense of affinity and affection toward children appearing in the 
video, linking them to their own grandchildren [98]; therefore, they were more willing to recommend a product to their families and friends when they saw its benefits for children. However, no significant difference emerged in the cognitive quiz scores across the three training groups. This finding can be explained by the limited learning time and the homogenous difficulty of the ten questions in the quiz. Additionally, the perceived difficulty regarding the quiz should have been asked to adjust the objective quiz scores [42]. Overall, these findings indicated the superiority of older adults as behavior models, compared with child and young adult models. Older adults, who may be only a little advanced in one or another area, are the ideal candidates to help their peers learn about information technologies.

\subsection{Limitations and Future Study}

The contributions of this study should be contingent upon its limitations. First, this study is a one-off training program instead of a longitudinal program. Therefore, the long-term outcomes of such an observational training design cannot be ascertained clearly. In fact, more longitudinal studies that follow older adults over long periods of training program and technology adoption are required, as older adults change throughout their lives. Future studies should endeavor to collect longitudinal data, such as after 3 weeks, 6 weeks, and 2 months of tablet use. However, this is challenging to do, as technologies are constantly changing and large-scale longitudinal studies are expensive to conduct. Additionally, the data in this study was only collected in Hong Kong, which is an Asian culture. As geographic and cultural features might influence one's attitudes and values, future research is encouraged to conduct comparative studies on Asian and non-Asian samples. Due to the small sample size for each group and confounding factors in this study, it is not valid to develop a robust regression analysis to discern the mechanism of which and how training outcomes influence technology acceptance of older adults. Future studies exploring the post-training technology acceptance mechanism need a larger sample size to perform regression analysis with various control variables such as education background and living arrangements to determine the strength of model identity on the training outcomes.

\section{Conclusions}

In addition to the originality of this study in focusing on enhancing the intention of older adults in using technology through training, this study goes further than previous studies by investigating various training outcomes. Compared with other training studies using behavior modeling for younger people, the present study uniquely examined the moderating effects of model identity on training outcomes of older adults. In addition, this study reaffirmed previous studies by explaining the behavior intention of technology acceptance in older adults and extended previous studies by exploring the mechanism in the post-training stage, incorporating affective and meta-cognitive outcomes.

Through empirical training experiments, this study found that observational training, through behavior modeling, is an effective intervention for (re)shaping the perceptions of older adults toward using technological devices. That is, with appropriate training, positive cognition effects (such as social connectedness) can be reinforced, while negative cognitions (such as cost) can be reduced. Behavior modeling through videos is suggested as an economical training method which can be easily implemented in elderly community centers and used for self-learning. In particular, the older adult behavior model is more effective than the young or child model in teaching older adults to use technology and reducing technology anxiety, as evidenced in this study. The identity-consistency of the behavior model enhances positive effects when designing videotapes for training purposes or even for advertisements. Therefore, besides peer learning, peer training is a promising tool for the education of older adults. The expectation of social inclusion is intense among older adults for their well-being. At post-training stage, social connectedness plays a more important role in affecting technology acceptance in older adults than self-efficacy and outcome expectations. The differences found before and after training indicate that investigating the mechanism of technology acceptance in specific adoption stages in future studies is of interest. Additionally, experienced costs are equally important to older adults 
as experienced benefits when deciding whether to use a technology device; that is, they paid much attention to the costs of learning. Therefore, avoiding complex demonstrations during training and trying to emphasize the benefits of a target technology device/activity are highly encouraged.

The effectiveness of the observational training in this study provides empirical evidence, and therefore confidence, for technology trainers, family caregivers, business organizations, relevant government offices, and non-governmental organizations to supply technology training activities tailored specifically to older adults in order to enhance their technology acceptance and adoption. As seen in this study, a promising approach is to help older adults to learn how to handle modern devices by integrating a training application into the product itself [99]. The results also offer ideas to industrial engineering managers, technology developers, and technology interface designers on the design integrated technology support for older adults; for example, training videos embedded in mobile applications. In line with the concept of lifelong learning, education opportunities should also be available to older people, not just children and young people [100]. The sustainable development of learning for older people must involve more effective digital training contents. Most older people still lack formal training services, access to technology trainings, and opportunities to experience innovative technology in community centers, product experience centers, and in a family context, which are in pressing need. Increasing the intention of older adults to use technologies will bridge the digital divide caused by aging and increase the penetration of emerging technology products, which may help facilitate independent living in older adults.

Author Contributions: Conceptualization, Q.M., A.H.S.C, and P.-L.T.; Methodology, Q.M., A.H.S.C., and P.-L.T.; Formal analysis, Q.M.; Writing-original draft, Q.M.; Writing-review and editing, A.H.S.C. and P.-L.T. All authors have read and agreed to the published version of the manuscript.

Funding: This study was funded by National Natural Science Foundation of China, Grant Number 71804007.

Acknowledgments: This study was supported by a local community center, "The Salvation Army Chuk Yuen Centre for Senior Citizens", in Hong Kong. The authors thank all participants and facilitators in the center for their great help and considerate cooperation in this study.

Conflicts of Interest: The authors declare no conflict of interest.

\section{References}

1. Van Volkom, M.; Stapley, J.C.; Malter, J. Use and Perception of Technology: Sex and Generational Differences in a Community Sample. Educ. Gerontol. 2013, 39, 729-740. [CrossRef]

2. Chumbler, N.R.; Mann, W.C.; Wu, S.; Schmid, A.; Kobb, R. The association of home-telehealth use and care coordination with improvement of functional and cognitive functioning in frail elderly men. Telemed. J. e-Health 2004, 10, 129-137. [CrossRef] [PubMed]

3. Cotten, S.R.; Yost, E.A.; Berkowsky, R.W.; Winstead, V.; Anderson, W.A. Designing Technology Training for Older Adults in Continuing Care Retirement Communities. Early Dev. Parent. 2016, 4, 157-159.

4. Sayago, S.; Blat, J. Telling the story of older people e-mailing: An ethnographical study. Int. J. Hum. Comput. Stud. 2010, 68, 105-120. [CrossRef]

5. Chen, K.; Chan, A. A review of technology acceptance by older adults. Gerontechnology 2011, 10, 1. [CrossRef]

6. Alvseike, H.; Brønnick, K. Feasibility of the iPad as a hub for smart house technology in the elderly; effects of cognition, self-efficacy, and technology experience. J. Multidiscip. Healthc. 2012, 5, 299-306. [CrossRef] [PubMed]

7. Niehaves, B.; Plattfaut, R. Internet adoption by the elderly: Employing IS technology acceptance theories for understanding the age-related digital divide. Eur. J. Inf. Syst. 2014, 23, 708-726. [CrossRef]

8. Blackler, A.L.; Mahar, D.P.; Popovic, V. Intuitive Interaction, Prior Experience and Aging: An Empirical Study. In Proceedings of the HCI 2009, Churchill College, Cambridge, UK, 1-5 September 2009.

9. Ejdys, J.; Halicka, K. Sustainable Adaptation of New Technology-The Case of Humanoids Used for the Care of Older Adults. Sustainability 2018, 10, 3770. [CrossRef]

10. Van Deursen, A.J.; Van Dijk, J.A. The first-level digital divide shifts from inequalities in physical access to inequalities in material access. New Media Soc. 2018, 21, 354-375. [CrossRef] 
11. Park, Y.J. My whole world's in my palm! The second-level divide of teenagers' mobile use and skill. New Media Soc. 2014, 17, 977-995. [CrossRef]

12. Tsai, H.-Y.S.; Shillair, R.; Cotten, S.R.; Winstead, V.; Yost, L. Getting Grandma Online: Are Tablets the Answer for Increasing Digital Inclusion for Older Adults in the US? Educ. Gerontol. 2015, 41, 695-709. [CrossRef] [PubMed]

13. Gil-Lacruz, A.I.; Gil-Lacruz, M.; Saz-Gil, M. Socially Active Aging and Self-Reported Health: Building a Sustainable Solidarity Ecosystem. Sustainability 2020, 12, 2665. [CrossRef]

14. Broady, T.; Chan, A.; Caputi, P.; Broady, T.R. Comparison of older and younger adults' attitudes towards and abilities with computers: Implications for training and learning. Br. J. Educ. Technol. 2010, 41, 473-485. [CrossRef]

15. Hickman, J.M.; Rogers, W.A.; Fisk, A.D. Training older adults to use new technology. J. Gerontol. Ser. B Psychol. Sci. Soc. Sci. 2007, 62, 77-84. [CrossRef]

16. Kher, H.V.; Downey, J.P.; Monk, E. A longitudinal examination of computer self-efficacy change trajectories during training. Comput. Hum. Behav. 2013, 29, 1816-1824. [CrossRef]

17. White, H.K.; McConnell, E.; Clipp, E.; Branch, L.G.; Sloane, R.; Pieper, C.; Box, T.L. A randomized controlled trial of the psychosocial impact of providing internet training and access to older adults. Aging Ment. Health 2002, 6, 213-221. [CrossRef]

18. Sterns, A.A. Curriculum design and program to train older adults to use personal digital assistants. Gerontologist 2005, 45, 828-834. [CrossRef]

19. Tsai, H.Y.S.; Shillair, R.; Cotten, S.R. Social support and "playing around" an examination of how older adults acquire digital literacy with tablet computers. J. Appl. Gerontol. 2017, 36, 29-55. [CrossRef]

20. Rogers, W.A.; Cabrera, E.F.; Walker, N.; Gilbert, D.K.; Fisk, A.D. A Survey of Automatic Teller Machine Usage across the Adult Life Span. Hum. Factors 1996, 38, 156-166. [CrossRef]

21. Mitzner, T.L.; Fausset, C.B.; Boron, J.B.; Adams, A.E.; Dijkstra, K.; Lee, C.C.; Rogers, W.A.; Fisk, A.D. Older Adults' Training Preferences for Learning to Use Technology. In Proceedings of the Human Factors and Ergonomics Society 52nd Annual Meeting, New York, NY, USA, 22-26 September; Sage Publications: Los Angeles, CA, USA, 2008; pp. 2047-2051. [CrossRef]

22. Wang, L.; Rau, P.-L.P.; Salvendy, G. Older Adults' Acceptance of Information Technology. Educ. Gerontol. 2011, 37, 1081-1099. [CrossRef]

23. Woodward, A.T.; Freddolino, P.P.; Blaschke-Thompson, C.M.; Wishart, D.J.; Bakk, L.; Kobayashi, R.; Tupper, C. Technology and Aging Project: Training Outcomes and Efficacy from a Randomized Field Trial. Ageing Int. 2010, 36, 46-65. [CrossRef]

24. Blit-Cohen, E.; Litwin, H. Elder participation in cyberspace: A qualitative analysis of Israeli retirees. J. Aging Stud. 2004, 18, 385-398. [CrossRef]

25. Mitzner, T.L.; Boron, J.B.; Fausset, C.B.; Adams, A.E.; Charness, N.; Czaja, S.J.; Dijkstra, K.; Fisk, A.D.; Rogers, W.A.; Sharit, J. Older adults talk technology: Technology usage and attitudes. Comput. Hum. Behav. 2010, 26, 1710-1721. [CrossRef] [PubMed]

26. Barnard, Y.; Bradley, M.D.; Hodgson, F.; Lloyd, A.D. Learning to use new technologies by older adults: Perceived difficulties, experimentation behaviour and usability. Comput. Hum. Behav. 2013, 29, 1715-1724. [CrossRef]

27. Renaud, K.; Van Biljon, J. Predicting Technology Acceptance and Adoption by the Elderly: A Qualitative Study. In Proceedings of the 2008 Annual Research Conference of the South African Institute of Computer Scientists and Information Technologists on IT Research in Developing Countries: Riding the Wave of Technology, Wilderness, South Africa, 6-8 October 2008; pp. 210-219.

28. Czaja, S.J.; Boot, W.R.; Charness, N.; Rogers, W.A. Designing for Older Adults: Principles and Creative Human Factors Approaches; CRC Press: Boca Raton, FL, USA, 2019.

29. Tsai, H.-Y.S.; Rikard, R.V.; Cotten, S.R.; Shillair, R. Senior technology exploration, learning, and acceptance (STELA) model: From exploration to use a longitudinal randomized controlled trial. Educ. Gerontol. 2019, 45, 728-743. [CrossRef]

30. Hickman, J.M.; Rogers, W.A.; Fisk, A.D. Age-related Effects of Training on Developing a System Representation. In Proceedings of the Human Factors and Ergonomics Society 47nd Annual Meeting, Denver, CO, USA, 13-17 October 2003; SAGE Publications: Los Angeles, CA, USA, 2003; pp. 1805-1809. 
31. Rogers, W.; Mitzner, T.; Sanford, J. A research framework to guide design of technologies for successful aging with disabilities. Gerontechnology 2014, 13, 272. [CrossRef]

32. Fishbein, M.; Ajzen, I. Belief, Attitude, Intention and Behavior: An Introduction to Theory and Research; Addison-Wesley: Reading, MA, USA, 1975.

33. Ajzen, I.; Joyce, N.; Sheikh, S.; Cote, N.G. Knowledge and the Prediction of Behavior: The Role of Information Accuracy in the Theory of Planned Behavior. Basic Appl. Soc. Psychol. 2011, 33, 101-117. [CrossRef]

34. Davis, F.D. Perceived Usefulness, Perceived Ease of Use, and User Acceptance of Information Technology. MIS Q. 1989, 13, 319-340. [CrossRef]

35. Rogers, E.M. Diffusion of Innovations; Simon and Schuster: New York, NY, USA, 2010.

36. Venkatesh, V.; Morris, M.G.; Davis, G.B.; Davis, F.D. User acceptance of information technology: Toward a unified view. MIS Q. 2003, 27, 425-478. [CrossRef]

37. Chen, K.; Chan, A.H.S. Gerontechnology acceptance by elderly Hong Kong Chinese: A senior technology acceptance model (STAM). Ergonomics 2014, 57, 635-652. [CrossRef]

38. Bandura, A. Social Foundations of Thought and Action: A Social Cognitive Theory; Prentice-Hall: Englewood Cliffs, NJ, USA, 1986.

39. Compeau, D.R.; Higgins, C.A. Computer Self-Efficacy: Development of a Measure and Initial Test. MIS Q. 1995, 19, 189. [CrossRef]

40. Gupta, S.; Bostrom, R.P.; Huber, M. End-user training methods. ACM SIGMIS Database 2010, 41, 9-39. [CrossRef]

41. Compeau, D.R.; Higgins, C.A. Application of Social Cognitive Theory to Training for Computer Skills. Inf. Syst. Res. 1995, 6, 118-143. [CrossRef]

42. Gupta, S.; Bostrom, R. Research Note-An Investigation of the Appropriation of Technology-Mediated Training Methods Incorporating Enactive and Collaborative Learning. Inf. Syst. Res. 2013, 24, 454-469. [CrossRef]

43. Bandura, A. Social Cognitive Theory of Mass Communication. Media Psychol. 2001, 3, 265-299. [CrossRef]

44. Yi, M.Y.; Davis, F.D. Developing and Validating an Observational Learning Model of Computer Software Training and Skill Acquisition. Inf. Syst. Res. 2003, 14, 146-169. [CrossRef]

45. Davis, F.D.; Yi, M.Y. Improving Computer Skill Training: Behavior Modeling, Symbolic Mental Rehearsal, and the Role of Knowledge Structures. J. Appl. Psychol. 2004, 89, 509-523. [CrossRef]

46. Chen, Y.; Wang, Q.; Xie, J. Online Social Interactions: A Natural Experiment on Word of Mouth versus Observational Learning. J. Mark. Res. 2011, 48, 238-254. [CrossRef]

47. Gist, M.E.; Schwoerer, C.; Rosen, B. Effects of alternative training methods on self-efficacy and performance in computer software training. J. Appl. Psychol. 1989, 74, 884-891. [CrossRef]

48. Struve, D.; Wandke, H. Video Modeling for Training Older Adults to Use New Technologies. ACM Trans. Access. Comput. 2009, 2, 1-24. [CrossRef]

49. Arenas-Gaitán, J.; Peral, B.; Jerónimo, M. Elderly and internet banking: An application of UTAUT2. J. Int. Bank. Commer. 2015, 20, 1-24.

50. Lam, J.C.; Lee, M.K. Digital Inclusiveness-Longitudinal Study of Internet Adoption by Older Adults. J. Manag. Inf. Syst. 2006, 22, 177-206. [CrossRef]

51. Charness, N.; Boot, W.R. Aging and Information Technology Use. Curr. Dir. Psychol. Sci. 2009, 18, $253-258$. [CrossRef]

52. Chen, K.; Chan, A.H.S. Predictors of gerontechnology acceptance by older Hong Kong Chinese. Technovation 2014, 34, 126-135. [CrossRef]

53. Al-Ammary, J. Factors Affecting the Acceptance and Use of Computers and the Internet by Elderly People in the Kingdom of Bahrain. In Proceedings of the International Conference on Information Management and Evaluation, Cape Town, South Africa, 25-26 March 2010; Academic Publishing: Reading, UK, 2010.

54. Hsiao, C.-H.; Tang, K.-Y. Examining a Model of Mobile Healthcare Technology Acceptance by the Elderly in Taiwan. J. Glob. Inf. Technol. Manag. 2015, 18, 292-311. [CrossRef]

55. Cornwell, B.; Laumann, E.O.; Schumm, P. The Social Connectedness of Older Adults: A National Profile. Am. Sociol. Rev. 2008, 73, 185-203. [CrossRef]

56. Chen, Y.-R.R.; Schulz, P.J.; Diviani, N.; Clemensen, J. The Effect of Information Communication Technology Interventions on Reducing Social Isolation in the Elderly: A Systematic Review. J. Med. Internet Res. 2016, 18, e18. [CrossRef] 
57. Delello, J.A.; McWhorter, R.R. Reducing the digital divide connecting older adults to iPad technology. J. Appl. Gerontol. 2017, 36, 3-28. [CrossRef]

58. Francis, J.; Rikard, R.; Cotten, S.R.; Kadylak, T. Does ICT Use matter? How information and communication technology use affects perceived mattering among a predominantly female sample of older adults residing in retirement communities. Inf. Commun. Soc. 2019, 22, 1281-1294. [CrossRef]

59. Aguinis, H.; Kraiger, K. Benefits of Training and Development for Individuals and Teams, Organizations, and Society. Annu. Rev. Psychol. 2009, 60, 451-474. [CrossRef] [PubMed]

60. Czaja, S.J.; Sharit, J. Designing Training and Instructional Programs for Older Adults; CRC Press: Boca Raton, FL, USA, 2012.

61. Woodward, A.T.; Freddolino, P.P.; Wishart, D.J.; Bakk, L.; Kobayashi, R.; Tupper, C.; Panci, J.; Blaschke-Thompson, C.M. Outcomes from a peer tutor model for teaching technology to older adults. Ageing Soc. 2012, 33, 1315-1338. [CrossRef]

62. Xie, B. Information Technology Education for Older Adults as a Continuing Peer-Learning Process: A Chinese Case Study. Educ. Gerontol. 2007, 33, 429-450. [CrossRef]

63. Fausset, C.B.; Harley, L.; Farmer, S.; Fain, B. Older adults' perceptions and use of technology: A novel approach. In Universal Access in Human-Computer Interaction. User and Context Diversity; Springer: Berlin/Heidelberg, Germany, 2013.

64. Luijkx, K.; Peek, S.; Wouters, E. "Grandma, you should do it-it's cool": Older adults and the role of family members in their acceptance of technology. Int. J. Environ. Res. Public Health 2015, 12, 15470-15485. [CrossRef] [PubMed]

65. Lin, Y.-C.; Liang, J.-C.; Yang, C.-J.; Tsai, C.-C. Exploring middle-aged and older adults' sources of Internet self-efficacy: A case study. Comput. Hum. Behav. 2013, 29, 2733-2743. [CrossRef]

66. Montero, P.J.R.; Chiva-Bartoll, O.; Salvador-García, C.; González-García, C. Learning with Older Adults through Intergenerational Service Learning in Physical Education Teacher Education. Sustainability 2020, 12, 1127. [CrossRef]

67. Abraham, C.; Michie, S. A taxonomy of behavior change techniques used in interventions. Health Psychol. 2008, 27, 379-387. [CrossRef]

68. Michie, S.; Richardson, M.; Johnston, M.; Abraham, C.; Francis, J.; Hardeman, W.; Eccles, M.P.; Cane, J.; Wood, C.E. The Behavior Change Technique Taxonomy (v1) of 93 Hierarchically Clustered Techniques: Building an International Consensus for the Reporting of Behavior Change Interventions. Ann. Behav. Med. 2013, 46, 81-95. [CrossRef]

69. Ma, Q.; Chen, K.; Chan, A.H.S.; Teh, P.-L. Acceptance of ICTs by Older Adults: A Review of Recent Studies. In Proceedings of the International Conference on Human Aspects of IT for the Aged Population, Los Angeles, CA, USA, 2-7 August 2015; pp. 239-249.

70. Burton-Jones, A.; Grange, C. From Use to Effective Use: A Representation Theory Perspective. Inf. Syst. Res. 2013, 24, 632-658. [CrossRef]

71. Sharit, J.; Czaja, S.J. Overcoming Older Adult Barriers to Learning through an Understanding of Perspectives on Human Information Processing. J. Appl. Gerontol. 2018, 39, 233-241. [CrossRef]

72. Waycott, J.; Pedell, S.; Vetere, F.; Ozanne, E.; Kulik, L.; Gruner, A.; Downs, J. Actively Engaging Older Adults in the Development and Evaluation of Tablet Technology. In Proceedings of the 24th Australian Computer-Human Interaction Conference, Melbourne, Australia, November 2012; Association for Computing Machinery: New York, NY, USA, 2012; pp. 643-652.

73. Murphy, C.A.; Coover, D.; Owen, S.V. Development and Validation of the Computer Self-Efficacy Scale. Educ. Psychol. Meas. 1989, 49, 893-899. [CrossRef]

74. Van Bel, D.T.; Smolders, K.; IJsselsteijn, W.A.; de Kort, Y. Social connectedness: Concept and measurement. Intell. Environ. 2009, 2, 67-74.

75. Wei, R.; Lo, V.-H. Staying connected while on the move. New Media Soc. 2006, 8, 53-72. [CrossRef]

76. Lee, R.M.; Draper, M.; Lee, S. Social connectedness, dysfunctional interpersonal behaviors, and psychological distress: Testing a mediator model. J. Couns. Psychol. 2001, 48, 310. [CrossRef]

77. Ajzen, I. Perceived Behavioral Control, Self-Efficacy, Locus of Control, and the Theory of Planned Behavior1. J. Appl. Soc. Psychol. 2002, 32, 665-683. [CrossRef]

78. Reichheld, F.F. The one number you need to grow. Harv. Bus. Rev. 2003, 81, 46-55. [PubMed] 
79. Sharit, J.; Czaja, S.J.; Perdomo, D.; Lee, C.C. A cost-benefit analysis methodology for assessing product adoption by older user populations. Appl. Ergon. 2004, 35, 81-92. [CrossRef] [PubMed]

80. Ma, Q.; Chan, A.H.S.; Chen, K. Personal and other factors affecting acceptance of smartphone technology by older Chinese adults. Appl. Ergon. 2016, 54, 62-71. [CrossRef]

81. Bandura, A. Vicarious and self-reinforcement processes. In The Nature of Reinforcement; Glaser, R., Ed.; Academic Press: New York, NY, USA, 1971; pp. 228-278.

82. Ebbers, S.J. Impact of Social Model Agent Type (Coping, Mastery) and Social Interaction Type (Vicarious, Direct) on Learner Motivation, Attitudes, Social Comparisons, Affect, and Learning Performance; The Florida State University: Tallahassee, FL, USA, 2007.

83. Park, J.; Han, S.H.; Kim, H.K.; Cho, Y. Developing Elements of User Experience for Mobile Phones and Services: Survey, Interview, and Observation Approaches. Hum. Factors Ergon. Manuf. Serv. Indust. 2011, 23, 279-293. [CrossRef]

84. Venkatesh, V.; Thong, J.Y.; Xu, X. Unified theory of acceptance and use of technology: A synthesis and the road ahead. J. Assoc. Inf. Syst. 2016, 17, 328-376. [CrossRef]

85. Lee, R.M.; Robbins, S.B. Measuring belongingness: The social connectedness and the social assurance scales. J. Couns. Psychol. 1995, 42, 232. [CrossRef]

86. Hair, J.F. Multivariate Data Analysis; Prentice Hall: Upper Saddle River, NJ, USA, 2010.

87. Ma, Q.; Chan, A.H.S.; Teh, P.L.; Poon, S.N. Over 60 and ICT: Exploring Factors That Affect Older Adults' ICTs Usage. In Proceedings of the International Conference on Human Aspects of IT for the Aged Population, Toronto, ON, Canada, 17-22 September 2016; pp. 196-208.

88. Venkatesh, V.; Bala, H. Technology Acceptance Model 3 and a Research Agenda on Interventions. Decis. Sci. 2008, 39, 273-315. [CrossRef]

89. Bradley, N.; Poppen, W. Assistive technology, computers and Internet may decrease sense of isolation for homebound elderly and disabled persons. Technol. Disabil. 2003, 15, 19-25. [CrossRef]

90. Giger, J.T.; Pope, N.D.; Vogt, H.B.; Gutierrez, C.; Newland, L.A.; Lemke, J.; Lawler, M.J. Remote patient monitoring acceptance trends among older adults residing in a frontier state. Comput. Hum. Behav. 2015, 44, 174-182. [CrossRef]

91. Teo, T.; Pok, S.H. Adoption of WAP-enabled mobile phones among Internet users. Omega 2003, 31, $483-498$. [CrossRef]

92. Turner, J.C.; Hogg, M.A.; Oakes, P.J.; Reicher, S.D.; Wetherell, M.S. Rediscovering the Social Group: A Self-Categorization Theory; Blackwell: Oxford, UK, 1987.

93. Hogg, M.A. Social identity theory. In Understanding Peace and Conflict through Social Identity Theory; Springer: Berlin/Heidelberg, Germany, 2016; pp. 3-17.

94. Kadylak, T.; Makki, T.W.; Francis, J.; Cotten, S.R.; Rikard, R.; Sah, Y.J. Disrupted copresence: Older adults' views on mobile phone use during face-to-face interactions. Mob. Media Commun. 2018, 6, 331-349. [CrossRef]

95. Lee, C.; Coughlin, J.F. Perspective: Older Adults' Adoption of Technology: An Integrated Approach to Identifying Determinants and Barriers. J. Prod. Innov. Manag. 2014, 32, 747-759. [CrossRef]

96. Zhou, J.; Zhang, B.; Tan, R.; Tseng, M.-L.; Zhang, Y. Exploring the Systematic Attributes Influencing Gerontechnology Adoption for Elderly Users Using a Meta-Analysis. Sustainability 2020, 12, 2864. [CrossRef]

97. Tootelian, D.H.; Varshney, S.B. The grandparent consumer: A financial "goldmine" with gray hair? J. Consum. Mark. 2010, 27, 57-63. [CrossRef]

98. Parida, B. Presence of Children in Advertisements and its impact on Consumers' Purchase Behaviour; IIM: Ahmedabad, India, 2013.

99. Bruder, C.; Blessing, L.; Wandke, H. Adaptive training interfaces for less-experienced, elderly users of electronic devices. Behav. Inf. Technol. 2013, 33, 4-15. [CrossRef]

100. Lee, Z.-J.; Huang, H.; Lee, C.-Y.; Jiang, Y.-H.; Chang, C.-Y. A Study on the Sustainable Development for Senior Learners. Sustainability 2019, 11, 6338. [CrossRef]

(C) 2020 by the authors. Licensee MDPI, Basel, Switzerland. This article is an open access article distributed under the terms and conditions of the Creative Commons Attribution (CC BY) license (http://creativecommons.org/licenses/by/4.0/). 